\section{ASCAMYCIN AND \\ DEALANYLASCAMYCIN, NUCLEOSIDE ANTIBIOTICS FROM STREPTOMYCES SP.}

Sir :

The antibiotic nucleocidin ${ }^{1)}$ represents highly cytotoxic 5'-O-sulfamoyl nucleosides whose sulfamoyl group is believed to simulate a phosphate group. Because of its un-ionized nature, the molecule can cross cellular membranes ${ }^{2,3}$. Recently, TAKAHASHI and BEPPU reported a nucleoside antibiotic AT-265, and the structure was proposed as 5'-O-sulfamoyl-2-chloroadenosine on the basis of spectral evidence ${ }^{4)}$. However, no direct proof was given regarding the configuration of this compound. More recently, we have isolated two nucleoside antibiotics from a fermentation broth of a Streptomyces. One of them was found to be identical with antibiotic AT-265, however, the other one was the structurally remarkable alanyl derivative of AT-265 and designated as ascamycin. We report here isolation, structure, and biological properties of these antibiotics. The structures were deduced from the spectral data including mass spectrometry, and the absolute configuration of ascamycin (1) as well as antibiotic AT-265 (2) (Scheme 1) was unambiguously established by their conversion to 2-chloroadenosine.

The organism was isolated from a soil sample collected in Hamamatsu-shi, Shizuoka-ken, Japan and taxonomic studies indicated that it belongs to Streptomyces. The strain was cultured in jar fermenters at $27^{\circ} \mathrm{C}$ in an organic medium. The fermentation broth was filtered

\section{Scheme 1.}
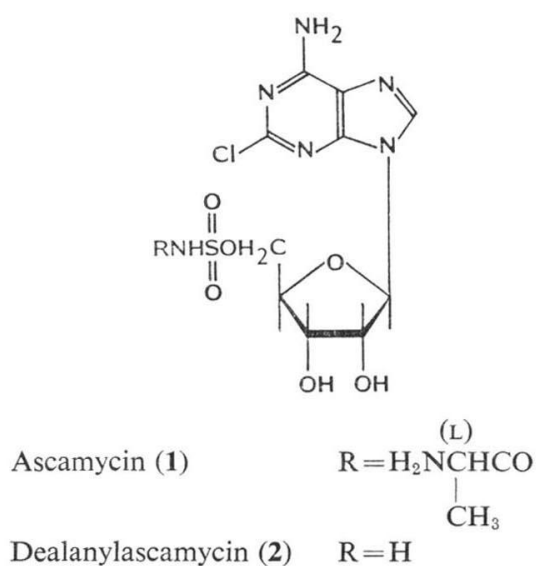

and the mycelium was extracted with $60 \%$ acetone. After removal of acetone, the extract was combined with the culture filtrate and passed through a column of Dowex 50WX8 $(\mathrm{H})$, which was eluted with $0.5 \mathrm{~N} \mathrm{NH}_{4} \mathrm{OH}$. The antibiotics were purified by chromatographies on charcoal (60\% acetone), Diaion HP-10 (10\% acetone), Sephadex LH-20 (10\% methanol), and Avicel cellulose $\quad\left(\mathrm{BuOH}-\mathrm{MeOH}-\mathrm{H}_{2} \mathrm{O}, \quad 4: 1: 0.5 \rightarrow\right.$ $4: 1: 1)$. 1 and 2 were separated by cellulose chromatography and they were further purified by silicic acid chromatography $\left(\mathrm{CHCl}_{3}-\mathrm{MeOH}\right)$. They were finally crystallized from aqueous ethanol. The yield of $\mathbf{1}$ and $\mathbf{2}$ was $20 \mathrm{mg}$ and $30 \mathrm{mg}$ respectively from 30 liters of the fermentation broth.

Ascamycin produces colorless needles with $\mathrm{mp}>270^{\circ} \mathrm{C}$. Positive ion fast atom bombardment (FAB) mass spectra* indicated the molecular formula $\mathrm{C}_{13} \mathrm{H}_{18} \mathrm{~N}_{7} \mathrm{O}_{7} \mathrm{SCl}: \mathrm{MH}^{+}$found $m / z$ 452.0760, calcd 452.0755. A clear monochloro isotope pattern is present in both positive and negative ion spectra. The exact molecular mass excludes presence of other halogen atoms. Hydrogen-deuterium exchange experiments carried out in conjunction with $\mathrm{FAB}^{5)}$ showed the presence of 7 active hydrogens $\left(\mathrm{MD}^{+} \mathrm{m} / \mathrm{z}\right.$ 460). It is an amphoteric compound and optically active, $[\alpha]_{D}^{20}+2.34^{\circ}\left(c 1, \mathrm{H}_{2} \mathrm{O}\right)$. The UV spectrum in water showed a maximum at 263 $\mathrm{nm}(\varepsilon 12,270)$, which is closely similar to that of 2-chloroadenosine. It is soluble in water and gave a positive reaction to permanganate, anisaldehyde- $\mathrm{H}_{2} \mathrm{SO}_{4}$, periodate-benzidine, and ninhydrin.

The other active compound (2) was crystallized from aqueous ethanol, $\mathrm{mp}>190^{\circ}(\mathrm{dec})$. It has the formula $\mathrm{C}_{10} \mathrm{H}_{13} \mathrm{~N}_{6} \mathrm{O}_{6} \mathrm{SCl}$ (positive ion $\mathrm{FAB}$ mass spectrum: $\mathrm{MH}^{+}$found $m / z 381.0380$, calcd 381.0383), which was found to be identical with antibiotic AT-265 by comparison with the authentic sample.

The presence of the alanyl group in $\mathbf{1}$ was indicated by the signals in ${ }^{1} \mathrm{H}$ and ${ }^{13} \mathrm{C}$ NMR $\left[\delta_{\mathrm{H}}^{\mathrm{D}_{2} \mathrm{O}} 1.27, \mathrm{~d}, J=7.0 \mathrm{~Hz}\left(-\mathrm{CH}_{3}\right), 3.65, \mathrm{q}(-\stackrel{\mathrm{CH}}{-})\right.$. $\delta_{\mathrm{C}}^{\mathrm{D}_{2} \mathrm{O}} 17.380\left(-\mathrm{CH}_{3}\right), \quad 52.206(-\mathrm{CH}-), 177.226$ $(\mathrm{C}=\mathrm{O})]$ in addition to the base and sugar signals

* MAT 731 mass spectrometer with Ion Tech FAB $11 \mathrm{~N}$ ion source, using a $6 \mathrm{KeV} \mathrm{Xe}$ beam. The sample was dissolved in glycerol $-\mathrm{H}_{2} \mathrm{O}(1: 1)$ prior to introduction. 


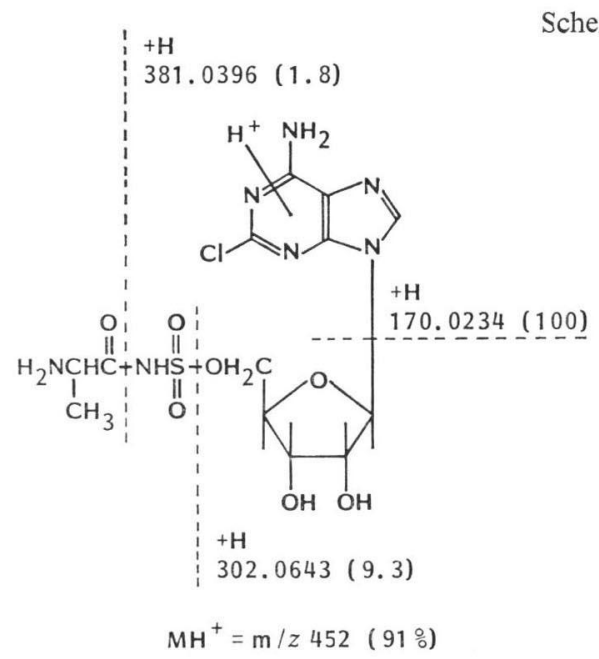

corresponding to those of $2\left(\delta_{\mathrm{H}}^{\mathrm{D}_{2} \mathrm{O}} 8.11,1 \mathrm{H}, \mathrm{s}\right.$, $8-\mathrm{H} ; 5.79,1 \mathrm{H}, \mathrm{d}, J=4.9 \mathrm{~Hz}, 1^{\prime}-\mathrm{H} ; 4.48,1 \mathrm{H}, \mathrm{t}$, $J=4.9 \mathrm{~Hz}, 2^{\prime}-\mathrm{H} ; 4.28,1 \mathrm{H}, \mathrm{t}, J=4.9 \mathrm{~Hz}, 3^{\prime}-\mathrm{H}$; $4.22,1 \mathrm{H}, \mathrm{m}, 4^{\prime}-\mathrm{H} ; 4.18,2 \mathrm{H}, \mathrm{dd}, J=9.6$ and $\left.3.0 \mathrm{~Hz}, 5^{\prime}-\mathrm{H}\right)$. Low field shift of $5^{\prime}-\mathrm{CH}_{2}$ indicated substitution at $5^{\prime}-\mathrm{O}$ of the sugar moiety. The position of alanine was deduced to be on the sulfamoyl-N as indicated by FAB mass spectrometry (Scheme 2). Hydrolysis of ascamycin with $0.5 \mathrm{~N} \mathrm{HCl}\left(100^{\circ} \mathrm{C}, 5\right.$ hours $)$ afforded L-alanine $\left.[\phi]_{218}^{\mathrm{H}_{2} \mathrm{O}}+760 \mathrm{pk}\right)$.

1 was trimethylsilylated using $\mathrm{N}, \mathrm{O}$-bis(trimethylsilyl)acetamide / trimethylchlorosilane / pyridine $(80: 1: 20)$ at $90^{\circ} \mathrm{C}, 1$ hour, which resulted in quantitative hydrolysis to provide a mass spectrum of a tetrasilyl derivative, essentially indistinguishable from that from $2\left(\mathrm{M}^{+} \mathrm{m} / z\right.$ 668). Cleavage of the 5'-O-sulfur bond confirms the absence of a $5^{\prime}$-amino group $(\mathrm{m} / \mathrm{z}$ 516.1679 , found; 516.1685 , calcd for $\mathrm{C}_{19} \mathrm{H}_{35}$ $\mathrm{N}_{5} \mathrm{O}_{4} \mathrm{ClSi}_{3}$ ), while the base +116 ion $^{8)}$ of $\mathrm{m} / \mathrm{z}$ 356 requires the absence of sugar substitution at $\mathrm{C}-1^{\prime}, 2^{\prime}$.

Dealanylation was most easily performed by incubation with Xanthomonas citri cells, giving dealanylascamycin (2) in quantitative yield. Finally, 2 was converted to the $5^{\prime}-O$-benzoyl derivative $\left[m / z 405 \mathrm{M}^{+}, 169 \mathrm{BH}^{+}, 284\left(\mathrm{M}-\mathrm{C}_{7} \mathrm{H}_{5} \mathrm{O}_{2}\right)^{+}\right]$by treatment with sodium benzoate in DMF $\left(100^{\circ} \mathrm{C}\right.$, 11 hours), which was then hydrolyzed with $0.5 \mathrm{~N}$ $\mathrm{KOH}$ at room temperature to give 2-chloro-9- $\beta$ D-ribofuranosyladenine ${ }^{7,8, \theta)},[\alpha]_{\mathrm{D}}^{22}-55.1^{\circ}(c 0.27$, EtOH). From the data described above, the absolute configuration of antibiotic AT-265 was determined to be 2-chloro-9- $\beta$-(5-O-sulfamoyl-D-

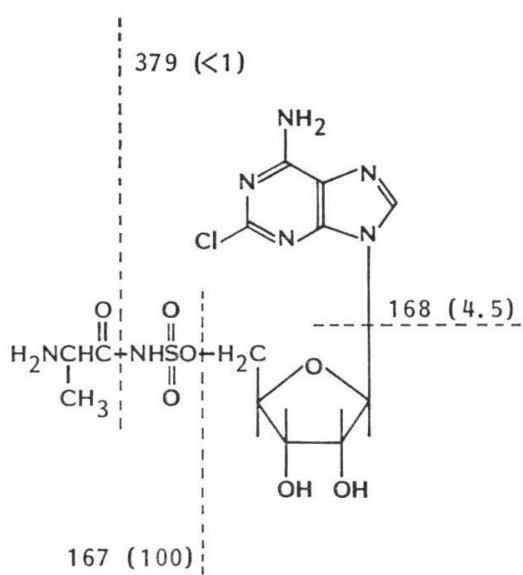

$$
(\mathrm{M}-\mathrm{H})^{-}=\mathrm{m} / 2450(88 \%)
$$

ribofuranosyl)adenine (2) and the structure of ascamycin is established as $9-\beta-[5-O-(N$-L-alanyl)sulfamoyl-D-ribofuranosyl]-2-chloroadenine (Scheme 1).

In contrast to the broad antimicrobial spectrum and extremely high toxicity to mice of $\mathbf{2}\left(\mathrm{LD}_{50}\right.$ $0.2 \mathrm{mg} / \mathrm{kg}$, mice, ip) ${ }^{1)}, \mathbf{1}$ showed strikingly selective antimicrobial activity. Minimal inhibitory concentration $(\mu \mathrm{g} / \mathrm{ml})$ : Xanthomonas citri 0.4, Xanthomonas oryzae 12.5, Mycobacterium phlei 12.5. Staphylococcus, Escherichia, Salmonella etc. were not sensitive. The toxicity to mice was one-sixteenth of 2. It is especially interesting that the incubation of $\mathbf{1}$ with Xanthomonas citri cells resulted in the rapid dealanylation to give $\mathbf{2}$ as described, while other resistant bacteria showed no such conversion, suggesting that this organism is sensitive to $\mathbb{1}$ because it posseses an enzyme which activates 1 by dealanylation. This may present a clue for introducing selective toxicity in the highly toxic 5'-O-sulfamoyl nucleosides. Sensitivity of a variety of prokaryotic and eukaryotic cells including mammalian tumor cells to this antibiotic is under investigation.

\section{Acknowledgment}

This work was supported in part by Grant in Aid for Cancer Research from the Ministry of Education, Science, and Culture (58010020) and in part by a grant from the National Institute of General Medical Sciences (GM 29812) in Japan. SKS was a National Cancer Institute postdoctral trainee (CA 09038). KI is grateful to Professor T. BEPPU for the sample of antibiotic AT-265. 


\section{KIYOSHI ISONO \\ Masakazu URAmoto \\ Hiroo Kusakabe}

The Institute of Physical and Chemical

Research,

Wako-shi, Saitama 351, Japan

NOBUO MiYata

TADAYOSHI KOYAMA

MaKoto Ubukata

Research Institute of Life Science,

Snow Brand Milk Product Co. Ltd., Ishibashi-machi, Shimotuga-gun, Tochigi 329-05, Japan

\section{Satinder K. Sethi}

JAMES A. MCCloskey

Departments of Medicinal Chemistry and Biochemistry, University of Utah, Salt Lake City, Utah 84112, U.S.A.

(Received March 12, 1984)

\section{References}

1) Suhadolnik, R. J.: Nucleoside Antibiotics. p. 246, Wiley Interscience, New York, 1970

2) Shuman, D. A.; R. K. Robins \& M. J. Robins: The synthesis of adenine 5'-O-sulfamoyl nucleosides related to nucleocidin. J. Am. Chem.
Soc. $91: 3391 \sim 3392,1969$

3) Schuman, D. A. \& M. J. Robins: The synthesis of nucleoside sulfamates related to nucleocidin. J. Am. Chem. Soc. 92: 3434 3440, 1970

4) Takahashi, E. \& T. Beppu: A new nucleosidic antibiotic AT-265. J. Antibiotics 35: 939 947, 1982

5) Sethi, S. K.; D. L. Smith \& J. A. McCloskey: Determination of active hydrogen content by fast atom bombardment mass spectrometry following hydrogen-deuterium exchange. Biochem. Biophys. Res. Commun. 112: 126 131, 1983

6) Pang, H.; K. H. Schram, D. L. Smith, S. P. Gupta, L. B. Townsend \& J. A. McCloskey: Mass spectrometry of nucleic acid constituents. Trimethylsilyl derivatives of nucleosides. J. Org. Chem. 47: 3923 3932, 1982

7) Davoll, J. \& B. A. Lowry: Some synthetic analogs of the natural purine nucleosides. J. Am. Chem. Soc. 74: 1563 1566, 1952

8) Shafffer, H. J. \& H. J. Thomas: Synthesis of potential anticancer agents. XIV. Ribosides of 2,6-disubstituted purines. J. Am. Chem. Soc. $80: 3738 \sim 3742,1958$

9) SAto, T.: Synthetic Procedures in Nucleic Acid Chemistry. Ed., W. W. ZORBACH \& R. S. TIPson, vol. 1, p. 264, Whiley Intersci., New York, 1968 